\section{Trace element composition and stability of the hydroxysulfate mineral schwertmannite}

QIAN CHEN, DAVID COHEN AND MARTIN ANDERSEN

University of New South Wales

Presenting Author: d.cohen@unsw.edu.au

In oxidising surficial environments, Fe mineralogy is generally dominated by $\mathrm{Fe}(\mathrm{III})$ oxy(hydr)oxides such as goethite. Under highly acidic and sulfate-rich conditions $\mathrm{Fe}$ may precipitate as the hydroxysulfato minerals jarosite or schwertmannite. The mobility of potentially toxic metals in terrestrial environments is partly dependent on the stability of such phases given their capacity to trap a range of toxic metals via co-precipitation, substitution or adsorption. Schwertmannite has, however, been considered relatively metastable ${ }^{[1,2]}$

This study examined Fe-rich precipitates in sediment profiles collected from the stream draining the Sunny Corner Ag-Pb- $\mathrm{Zn}$ mine that ceased operations in the 1920s, including indications of long-term stability of schwertmannite in and the retention of various trace metals. As mineralogical analysis of schwertmannite by physical methods such as XRD is hampered by its poor crystallinity, a four-step sequential geochemical extraction ${ }^{[3]}$ was also used to examine the relationship between mineralogy and trace element concentrations. Two steps involved digestions aimed at dissolution of schwertmannite: $0.25 \mathrm{M}$ hydroxylamine. $\mathrm{HCl}$ in $\mathrm{pH} 1 \mathrm{HCl}$ ("weak hydroxylamine") and $1 \mathrm{M}$ hydroxylamine. $\mathrm{HCl}$ in $25 \%$ acetic acid ("strong ahydroxylamine") with nearly all $\mathrm{Fe}$ and contained $\mathrm{Cu}, \mathrm{Pb}$ and As extracted in these two steps.

Mineralogy of sediment profiles in the main stream draining the mine waters did not vary substantially from base to top, and is dominated by schwertmannite with lesser amounts (with sharper XRD peaks) of jarosite and quartz (Fig 1). Weak hydroxylamine progressively released $\mathrm{Fe}$ and $\mathrm{S}$ on an 8:1.4 molar ratio and various trace elements congruently over $24 \mathrm{hr}$ digestions (Fig 2). Strong hydroxylamine digestion mainly attacked schwertmannite with an Fe:S molar ratio of 8:1 but containing much higher $\mathrm{Pb}$ and As concentrations. Jarosite was relatively insoluble.

Schwertmannite may be stable for substantial periods (decades) under highly acidic sulfate-rich conditions. Selective extractions indicate two schwertmannites present at Sunny Corner, though it is not clear whether the latter represents a recrystallised or matured version of the former, or contemporaneous precipitation under slightly varying environmental conditions.

[1] Bigham et al. (1994) Min. Mag. 58, 641-648.

[2] Schwertmann \& Carlson (2005) Clay Minerals 40, 63-66.

[3] Mokhtari et al. (2009) GEEA. 9, 227-236.
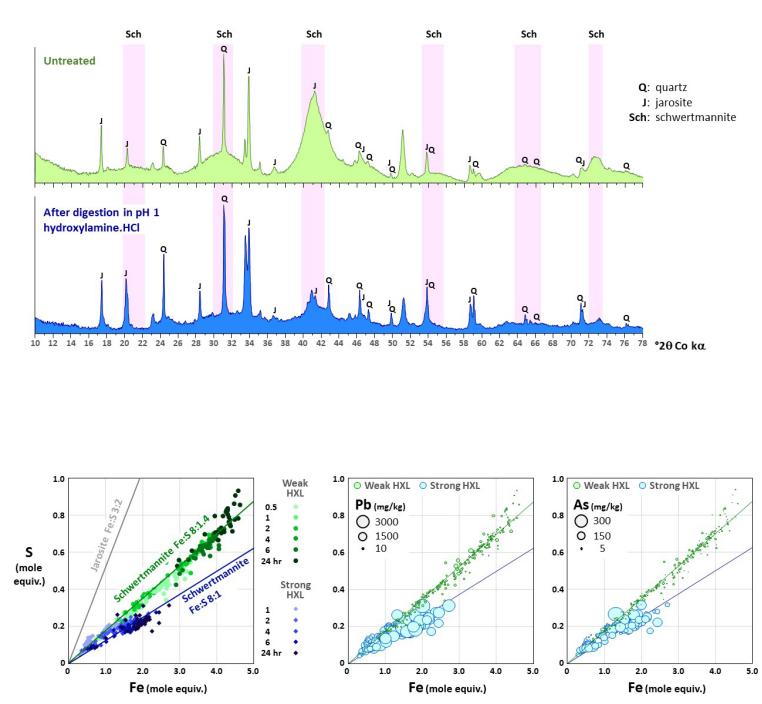